\title{
Lung function and radiographic change in chrysotile workers in Swaziland
}

\author{
MARGERY MCDERMOTT, ${ }^{1}$ MARGARET M BEVAN,${ }^{1} \mathrm{P}$ C ELMES, ${ }^{1} \mathrm{~J}$ T ALLARDICE, ${ }^{2 *}$ \\ AND A C BRADLEY ${ }^{3} \dagger$ \\ From the MRC Pneumoconiosis Unit, ${ }^{1}$ Cardiff, Turner and Newall Ltd, ${ }^{2}$ Manchester, and Havelock Mine, ${ }^{3}$ \\ Swaziland
}

ABSTRACT The effect on lung function and radiographic indices of exposure to chrysotile asbestos was investigated by cross-sectional studies in two groups of men at Havelock Mine, Swaziland. The first group consisted of 214 employees and ex-employees, mean age 52, who had been employed for at least 10 years, and whose dust exposure ranged from minimal for surface workers to very heavy for those in the grading and bagging sections of the mill. In this group $29 \%$ had category 1 or more simple pneumoconiosis and $4.5 \%$ category 2 or more. For surface and mine workers, the estimated annual deterioration in FEV $\mathrm{F}_{1}$ and FVC and the increase in category of pneumoconiosis was similar to that due to age alone, while the heaviest exposure almost doubled the decline in lung function and trebled the rate of progression of pneumoconiosis. The second group consisted of 224 men, mean age 33, all currently working in the mill and having been employed there for at least a year. In this group $30 \%$ had category 1 or more simple pneumoconiosis, and $2.7 \%$ category 2 . Exposure in the dustiest sections of the mill more than doubled the estimated annual decline in lung function and doubled the rate of progression of pneumoconiosis.

The production of chrysotile asbestos is usually considered to be less hazardous to health than that of crocidolite and amosite. Rossiter $e^{a l^{1}}$ found a low level of asbestosis among workers in Canadian chrysotile mines compared with that reported from Italy. ${ }^{2}$ The aim of our investigation was to determine the extent of occupational lung disease among mill, mine, and surface workers at Havelock chrysotile mine, Swaziland, from where little asbestos-related disease had been reported. The lack of a serious hazard should be confirmed if the continued production of chrysotile is to be justified. The work force at Havelock consists of about 2000 Africans and 100 Europeans who form a community that is the third largest centre of population in Swaziland. The mine has been in full operation since the late 1930s, at which time most of the Africans were from Malawi, Mozambique, and South Africa; today, however, they are mainly Swazis.

${ }^{*}$ Present address: Employment Medical Advisory Service, Leeds.

†Present address: Office of the Medical Officer of Health, Port Elizabeth, South Africa.

Received 2 November 1981

Accepted 27 November 1981
We report two studies that took place about five months apart and have been treated separately.

\section{First study}

\section{METHODS}

An attempt was made to trace all men who had been employed for 10 years or more before 1970. A search of the mine records produced a list of 748 men, of whom 185 were still employed, 153 had left but still lived in Swaziland, 200 had moved to Malawi or Mozambique, and the remaining 210 had died. In the group of 338 living in Swaziland were 270 Swazis and 68 Europeans, of whom 235 Swazis and 36 Europeans attended the mine hospital for chest radiographs and examinations, lung function measurements, and to complete occupational histories and respiratory questionnaires. The respiratory symptoms are currently being analysed; the analysis described here is of lung function and radiographic data from the Swazis. Twelve of these, who were exposed to coal or silica dust in other occupations, were excluded as were nine with incomplete data or technically unsatisfactory results, leaving a group of 214 men. Figure 1 gives the distribution of age and years of employment. The mean 

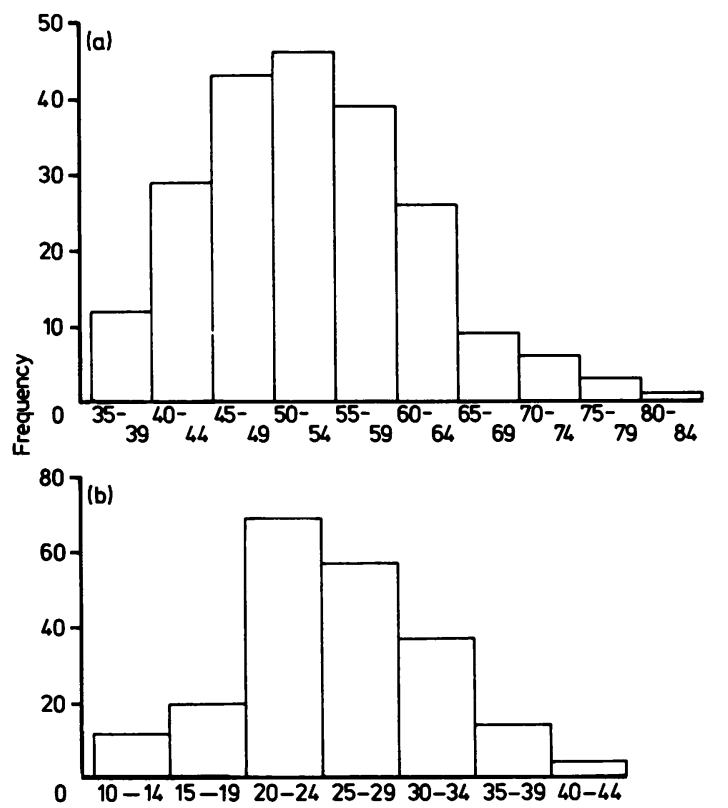

Fig 1 First study: distribution of (a) age and (b) years of employment.

age was 52 years and mean duration of employment 25 years.

The radiographs, after being placed in random order, were read by three experienced readers. The profusion of irregular and rounded small opacities was assessed according to the 12-point scale (categories $0 /-$ to $3 /+$ ) of the ILO classification, ${ }^{3}$ and the index of parenchymal change was taken as the median of the three readings. The categories 0 /to $3 /+$ were represented by numbers $1-12$ to facilitate numerical analysis.

The forced expiratory volume in one second $\left(F^{2} V_{1}\right)$ and forced vital capacity (FVC) were measured using a McDermott digital spirometer. Each subject's height was measured, and the FEV 1 and FVC expressed at a standard height of $1.7 \mathrm{~m}$, using the regression model proposed by Cole ${ }^{4}$ where each reading is multiplied by the factor $(1 \cdot 7 /$ height $){ }^{2}$

No accurate estimates of dust exposure are possible, as monitoring of the airborne dust was not started until 1976, when a major dust suppression programme began. Discussions with reliable, longservice employees, however, suggest that dust concentrations, particularly in the mill, had been extremely high in the past. They have compared previous conditions with a present, unmanned section in which the airborne dust concentration is about $50 \mathrm{fibres} / \mathrm{ml}\left(5 \times 10^{7} \mathrm{fibres} / \mathrm{m}^{3}\right)$. From their recollections, it seems that in most areas of the mill the reduction in visibility due to the airborne dust was similar to, or worse than, in this "reference" section, although, since about 1970 , some attempts had been made to reduce the dust concentrations. The proportion of fibrous dust varies among different areas of the mill, the lowest proportion being in the rock crushing plant. In the mine, which is wet, dust concentrations have always been considerably lower than in the mill. Asbestos is transported from Havelock on an aerial ropeway; it was originally packed in hessian sacks, which resulted in the workers on the ropeway receiving a high dust exposure. Since about 1970, however, polyethylene bags have been used thereby considerably reducing the dust concentration. No section of the workforce may be described as "non-exposed," as in dry, windy weather dust from the mill and waste tips is blown over the whole area, so that even estate workers are exposed to the "background" concentration. This concentration, too, is now lower than in the past as the waste tips have been dampened since about 1970.

The jobs listed in the men's occupational histories have each been allocated to one of six categories, $\mathrm{J} 1-\mathrm{J} 6$ in ascending order of dust exposure. As these divisions are based on crude estimates, there is no way of calculating the absolute dust concentrations in each location. Table 1 lists the categories.

Table 1 First and second studies. Allocation of jobs to category of dust exposure

\begin{tabular}{|c|c|}
\hline $\mathbf{J} 1$ & All surface jobs except road sweeping \\
\hline $\mathbf{J} 2$ & Mine \\
\hline $\begin{array}{l}\mathrm{J} 3 \\
\mathrm{~J} 4\end{array}$ & $\begin{array}{l}\text { Waste dump since } 1970 \\
\text { Aerial ropeway before } 1970 \\
\text { Road sweeping } \\
\text { Mill: rock crushing plant }\end{array}$ \\
\hline J5 & $\begin{array}{l}\text { Waste dump before } 1970 \\
\text { Mill: treatment, conditioning, and sample plants }\end{array}$ \\
\hline J6 & $\begin{array}{l}\text { Mill: grading and recovery plants } \\
\text { Fibre storage } \\
\text { Bagging }\end{array}$ \\
\hline
\end{tabular}

For workshop and maintenance workers who entered the mill regularly, their exposure has been calculated as equivalent to one day a week in $\mathrm{J} 5$.

\section{Results}

Figure 2 shows the distribution of parenchymal change $-29 \%$ of the men had category 1 or more pneumoconiosis, $4.5 \%$ category 2 or more, and $1.5 \%$ category 3 .

A multiple regression analysis has been used to relate lung function and radiographic indices to age and exposure. Table 2 shows the numbers of men who worked at any time in each of the six categories of exposure, from which it may be seen that, except 


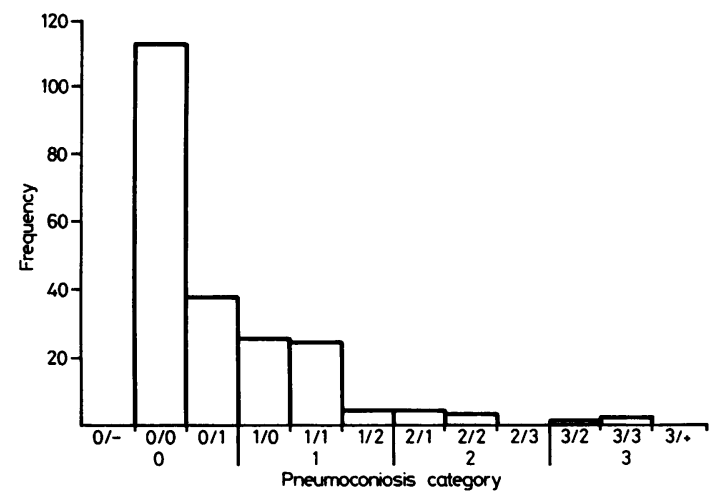

Fig 2 First study: distribution of parenchymal change.

Table 2 First study: number of men in each exposure category

\begin{tabular}{|c|c|c|c|c|}
\hline \multirow[t]{2}{*}{ Category } & \multicolumn{2}{|c|}{$\begin{array}{l}\text { Men who worked at } \\
\text { any time in category }\end{array}$} & \multirow{2}{*}{$\begin{array}{l}\text { Men with } \\
\text { exposure in no } \\
\text {-other category }\end{array}$} & \multirow{2}{*}{$\begin{array}{l}\text { Men with } \\
\text { exposure in no } \\
\text { other category } \\
\text { except } J 1\end{array}$} \\
\hline & No & $\begin{array}{l}\text { Mean exposure } \\
\text { (years) }\end{array}$ & & \\
\hline $\begin{array}{l}\mathrm{J} 1 \\
\mathrm{~J} 2 \\
\mathrm{~J} 3 \\
\mathrm{~J} 4 \\
\mathrm{~J} 5 \\
\mathrm{~J} 6\end{array}$ & $\begin{array}{r}143 \\
102 \\
26 \\
27 \\
63 \\
25\end{array}$ & $\begin{array}{r}16.4 \\
14.7 \\
11.8 \\
10.1 \\
11.0 \\
9.3\end{array}$ & $\begin{array}{r}38 \\
32 \\
0 \\
4 \\
11 \\
3\end{array}$ & $\begin{array}{r}-65 \\
12 \\
10 \\
24 \\
9\end{array}$ \\
\hline
\end{tabular}

for $\mathrm{J} 1$ and $\mathrm{J} 2$, few men worked in one category alone; even when $\mathbf{J} 1$, the background level, is discounted, the numbers in all categories except for $\mathrm{J} 2$ are too small for separate analyses. As already men- tioned, it is impossible to relate numerically the exposure levels in the six categories; hence, each has been treated as a separate variable.

Table 3 gives the results of the multiple regression analysis which shows that exposure in categories $\mathrm{J} 1-\mathrm{J} 4$ produces no significant deterioration in any of the indices, while all indices deteriorate significantly with age. Exposure in categories J5 and J6 significantly reduces FVC and increases the profusion of small opacities, while $F E V_{1}$ is significantly reduced in J6. The FEV ${ }_{1} / F V C \%$ appears to be unaffected by exposure, even at the highest level.

This table also shows the effect of excluding categories $\mathrm{J} 1$ - $\mathrm{J} 4$ from the analysis; some significance levels are increased and the effect of $\mathrm{J} 5$ on the FEV has become significant. The annual decline in $F E_{1}$ in category $\mathrm{J} 5$ is $40 \%$ greater than that due to age alone, and in $\mathrm{J} 680 \%$ greater, while for FVC the figures are $60 \%$ and $90 \%$ respectively. The increase in profusion of small opacities in $\mathrm{J} 5$ is slightly more than in J6; in both categories it is over three times greater than that due to age alone. Using the regression equations, the effect on the FEV ${ }_{1}$ and FVC of a man working from 20 to 60 years of age in either of the two dustiest categories has been estimated (fig 3).

The total number of men who were exposed to the highest dust concentrations in categories $\mathrm{J} 5$ and $\mathrm{J} 6$ is 77; fig 4 shows the distribution of parenchymal change in this group compared with that of the 137 men who worked only in the lower exposure categories $\mathrm{J} 1-\mathrm{J} 4$. Of the men in the low-exposure group, $22 \%$ had category 1 or more pneumoconiosis compared with $43 \%$ in the high-exposure group.

Table 3 First study: dependence of lung function and radiographic indices on age and years of exposure in all six dust categories and in the two dustiest categories

\begin{tabular}{|c|c|c|c|c|c|c|c|c|}
\hline \multirow[t]{2}{*}{ Index } & \multicolumn{7}{|c|}{ Regression coefficients of index on age and years in category } & \multirow[t]{2}{*}{ Constant } \\
\hline & Age & $J 1$ & $J 2$ & $J 3$ & $J 4$ & $J 5$ & J6 & \\
\hline \multicolumn{9}{|l|}{$\begin{array}{l}\text { In all six dust } \\
\text { categories }\end{array}$} \\
\hline $\begin{array}{l}\text { FEV } \\
\text { FVC } \\
\text { FEV/FVC\% } \\
\text { Parenchymal } \\
\text { Change }{ }^{\dagger}\end{array}$ & $\begin{array}{l}-0.027^{* * *} \\
-0.024^{* * *} \\
-0 \cdot 294^{* * *} \\
1+0.033^{* *}\end{array}$ & $\begin{array}{l}-0.003 \\
-0.007 \\
+0.040 \\
-0.015\end{array}$ & $\begin{array}{l}0 \\
-0.002 \\
+0.046 \\
0\end{array}$ & $\begin{array}{l}-0.011 \\
-0.011 \\
-0.151 \\
-0.023\end{array}$ & $\begin{array}{l}-0.005 \\
-0.009 \\
-0.040 \\
+0.029\end{array}$ & $\begin{array}{l}-0.014 \\
-0.021^{*} \\
-0.008 \\
+0.073^{* * *}\end{array}$ & $\begin{array}{l}-0.023^{*} \\
-0.028^{*} \\
-0.091 \\
+0.061^{*}\end{array}$ & $\begin{array}{r}3.97 \\
4.95 \\
84.88 \\
1.23\end{array}$ \\
\hline \multicolumn{9}{|l|}{$\begin{array}{l}\text { In two dustiest } \\
\text { categories }\end{array}$} \\
\hline FEV & $-0 \cdot 027 \pm 0 \cdot 004^{* * *}$ & & & & & $-0.011 \pm 0.005^{*}$ & $-0.021 \pm 0.009^{*}$ & 3.94 \\
\hline $\begin{array}{l}\text { FVC } \\
\text { FEV/FVC\% }\end{array}$ & $\begin{array}{l}-0.025 \pm 0.005^{* * *} \\
-0.286 \pm 0.073^{* * *}\end{array}$ & & & & & $\begin{array}{l}-0.016 \pm 0.006^{* *} \\
-0.030 \pm 0.084\end{array}$ & $\begin{array}{l}-0.022 \pm 0.010^{*} \\
-0.120 \pm 0.150\end{array}$ & $\begin{array}{r}4 \cdot 89 \\
85 \cdot 09\end{array}$ \\
\hline $\begin{array}{l}\text { Parenchymal } \\
\text { Change } f\end{array}$ & $1+0.032 \pm 0.012^{* *}$ & & & & & $+0 \cdot 081 \pm 0.014^{* * *}$ & $+0.068 \pm 0.024^{* *}$ & 1.09 \\
\hline
\end{tabular}

†Categories $0 /-$ to $3 /+$ represented by Nos $1-12$.

${ }_{* * *}^{* *} \mathrm{p}<0.001$

$\begin{array}{ll}* * & \mathrm{p}<0.01 . \\ * & \mathrm{p}<0.05 .\end{array}$ 


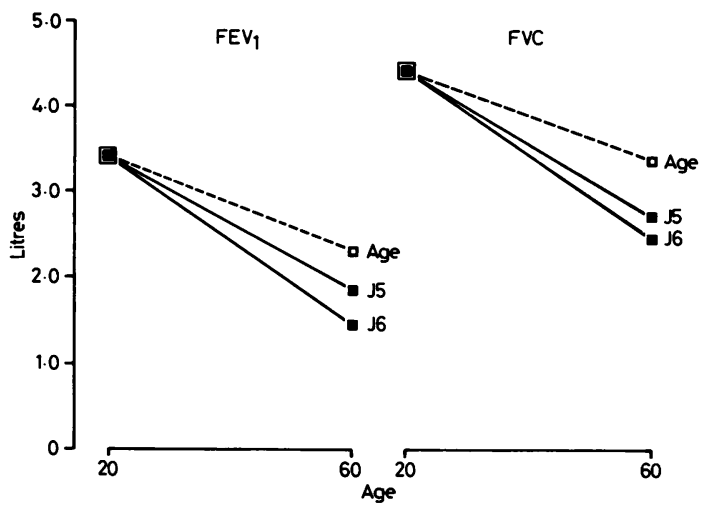

Fig 3 First study: effect of age and dust exposure on FEV and FVC.
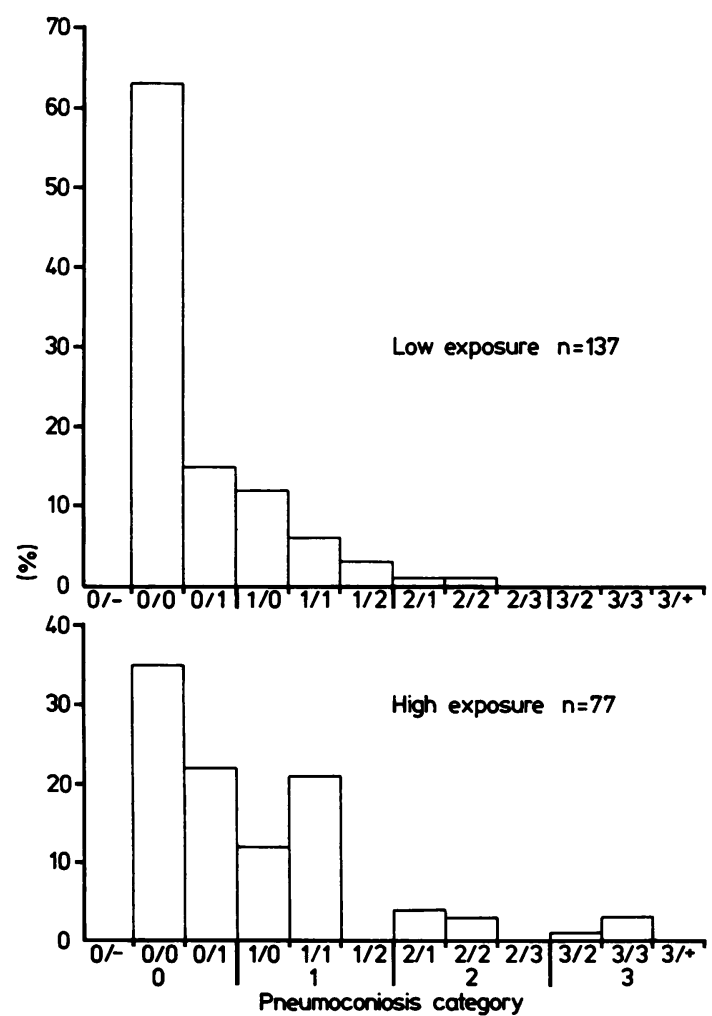

Fig 4 First study: distribution of parenchymal change in high-exposure and low-exposure groups.

\section{EFFECT OF SMOKING}

Of the 214 men in the sample, $10 \%$ were exsmokers and $38 \%$ smokers, mostly of pipes and hand-rolled cigarettes, with some manufactured cigarettes. Only imprecise estimates of the amount smoked could be obtained, but the average daily tobacco consumption was certainly under $10 \mathrm{~g}$ and probably only about $4 \mathrm{~g}$. When the effect of dust exposure is ignored, there are no significant differences between smokers and non-smokers in $\mathrm{FEV}_{1}$, FVC, or parenchymal change. The $\mathrm{FEV}_{1} / \mathrm{FVC}^{2}$ is significantly lower, however, in smokers than in non-smokers $(\mathrm{p}<0.001)$.

The effect of dust exposure in smokers is not significantly different from that in non-smokers for any of the lung function indices. In category J6, however, the increase in profusion of small opacities is significantly greater in non-smokers than in smokers $(p<0.05)$.

\section{Second study}

\section{METHODS}

As the men working in the mill are exposed to a considerably higher concentration of dust than those in the mine or in surface jobs, the second group was chosen to consist of all current mill employees except for those included in the first study. A total of 273 men attended the mine hospital and were tested as before. Twelve Europeans have again been excluded, while of the 261 Swazis, 17 had incomplete data or technically unsatisfactory results and a further 20 had been exposed to silica or had worked in the mill for under a year. The mean age of the remaining 224 men was 33 years and mean duration of employment eight years, the distributions being shown in fig 5 . The lung function was measured by the medical staff at the mine, using a Vitalograph, and the chest radiographs were read as before by the same three readers. The jobs have again been allocated to categories $\mathrm{J} 1-\mathrm{J} 6$ (table 1), each man being currently employed in one of the mill categoriesthat is $\mathrm{J} 4,5$, or 6 .

RESULTS

Figure 6 shows the distribution of parenchymal change $-30 \%$ of the men had category 1 or more pneumoconiosis and $2.7 \%$ category 2 , while there were none with category 3 . Table 4 shows the number of men who worked at any time in each of the exposure categories and the mean duration of exposure.

As in the first study, lung function and radiographic indices have been related to age and exposure by multiple regression analysis, using categories $\mathrm{J4}$, 5 , and 6 only, and again treating each as a separate variable. The results of the analysis are shown in table 5. Although the men are much younger, and have worked in the dust for shorter periods than those in the first group, the deterioration in the indices due to exposure is again clearly shown. Parenchymal change, $\mathrm{FEV}_{1}$, and FVC are all significantly affected by exposure in $\mathrm{J} 5$ and J6, while the FEV 1 / 


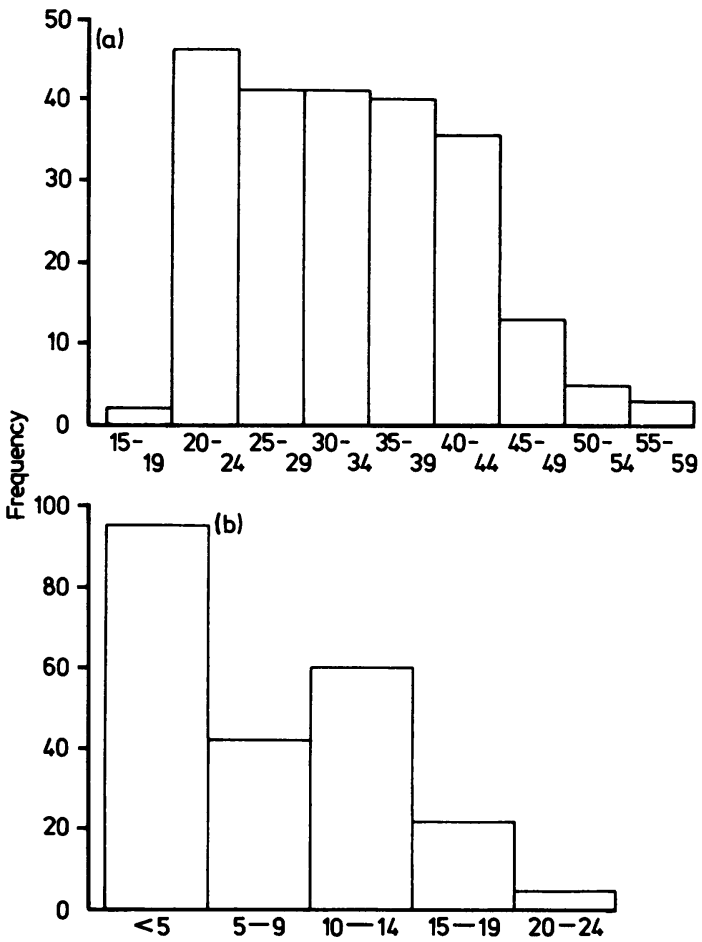

Fig 5 Second study: distribution of $(a)$ age and $(b)$ years of employment.

Table 4 Second study: number of men in each exposure category

\begin{tabular}{lcl}
\hline Category & \multicolumn{2}{c}{ Men who worked at any time in category } \\
\cline { 2 - 3 } & No & Mean exposure (years) \\
\hline J1 & 19 & $4 \cdot 9$ \\
J2 & 17 & $4 \cdot 5$ \\
J3 & 1 & $4 \cdot 0$ \\
J4 & 20 & $6 \cdot 0$ \\
J5 & 147 & $6 \cdot 8$ \\
J6 & 89 & $4 \cdot 6$ \\
\hline
\end{tabular}

FVC\% is again unaffected. In the rock crushing plant (J4), which has the lowest proportion of fibrous dust, the effect of exposure is not significantly different from that of age for any of the indices. The regression coefficient of parenchymal change for $\mathrm{J} 4$, although greater than for $\mathrm{J} 5$, is not statistically significant as there are only 20 men in the category.

Table 5 also shows the effect of excluding $\mathrm{J} 4$ from the analysis. Exposure in $\mathrm{J} 5$ almost doubles the annual decline in FEV ${ }_{1}$ and more than doubles that in FVC, while in $\mathrm{J} 6$ the decline in $\mathrm{FEV}_{1}$ is more than doubled and that in FVC trebled. The increase in

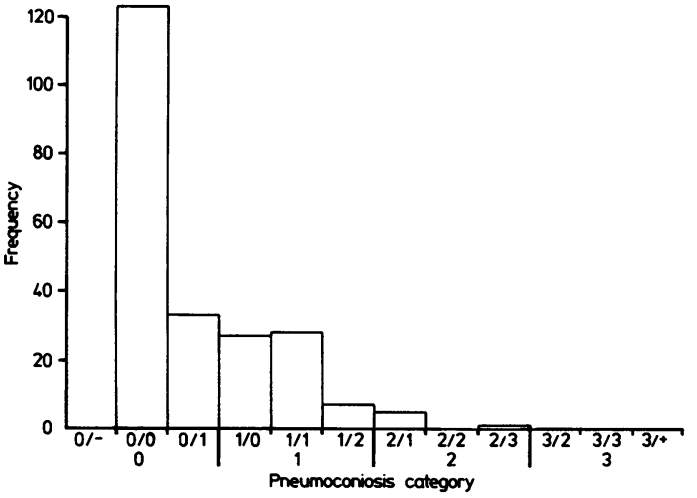

Fig 6 Second study: distribution of parenchymal change.

profusion of small opacities for men in J5 is no longer significantly different from that due to age alone, but for men in $\mathrm{J} 6$ it is doubled. Figure 7 shows the estimated effect on FEV 1 and FVC of a man working from age 20 to age 60 in either of the two dustiest categories.

\section{EFFECT OF SMOKING}

In this sample $4 \%$ were ex-smokers and $33 \%$ smokers, with smoking habits similar to those in the first sample. As before, estimates of the amount smoked are not accurate, but the average was probably $3-4 \mathrm{~g}$ daily. There are no significant differences between smokers and non-smokers in any of the indices, and the effect of dust exposure in smokers is not significantly different from that in non-smokers.

\section{Discussion}

The incidence of parenchymal change category 1 or more is similar in both studies, being $29 \%$ in the first, older group and $30 \%$ in the younger. The younger group, however, were all employed in the mill, $93 \%$ having exposure in $\mathrm{J} 5$ and $\mathrm{J} 6$, while only $36 \%$ of the older group ever worked in these dustiest areas. In Quebec mine and mill workers with 10-30 years' exposure the incidence of parenchymal change category 1 or more was $5 \%,{ }^{1}$ while Ghezzi et $a l^{2}$ reported an incidence of $29.8 \%$ among workers exposed for at least one year in an Italian chrysotile mine. In Corsica, of men examined 14 years after an 11-year exposure period, $40.3 \%$ were found to have parenchymal change category $1 / 1$ or more. ${ }^{5}$ In both groups of Swazis the increase in profusion of small opacities with age is statistically significant; this might be explained by the presence of the background dust over the area, to which, before the dampening of the tips, the whole population was constantly exposed. 
Table 5 Second study: dependence of lung function and radiographic indices on age and years of exposure in all three mill categories and in the two dustiest categories

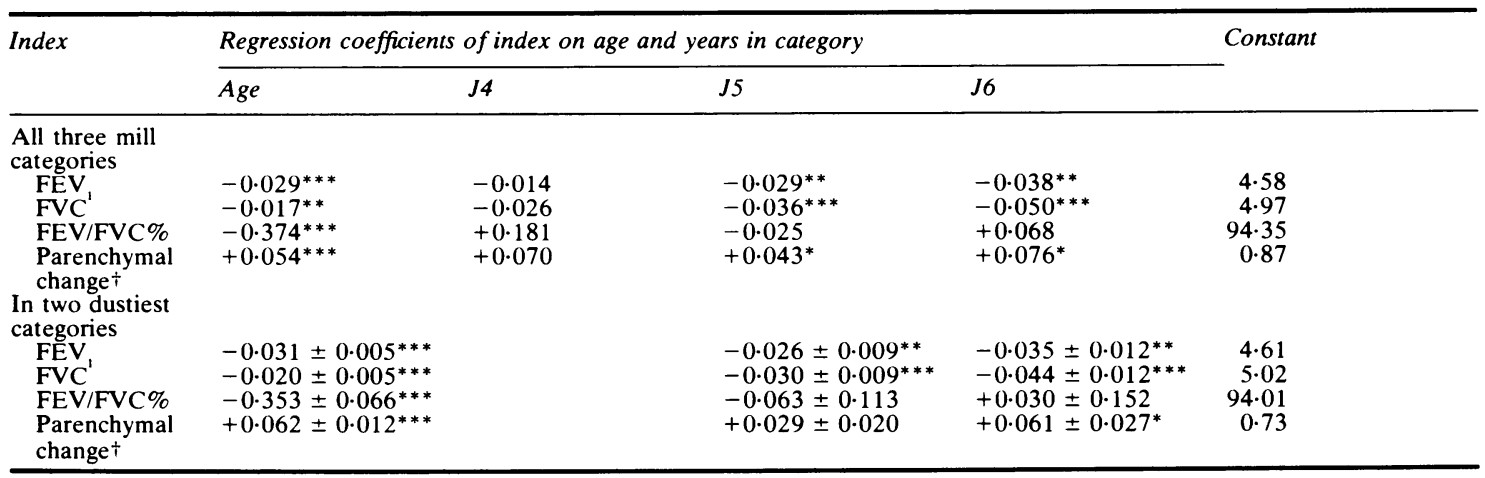

tCategories $0 /-$ to $3 /+$ represented by Nos $1-12$.

$* * \mathrm{p}<0.001$.

$* * \mathrm{p}<0.01$.

$* \quad \mathrm{p}<0.05$.

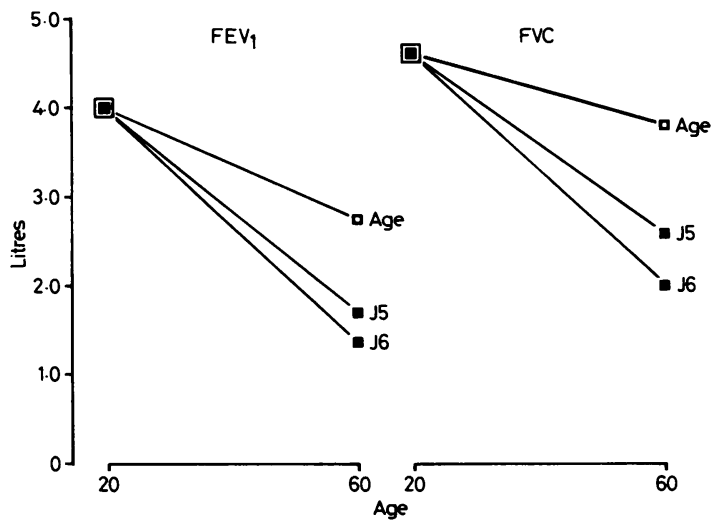

Fig 7 Second study: effect of age and dust exposure on $F E V_{1}$ and FVC.

The results of the first study have shown that exposure in any part of the mill, with the exception of the rock crushing plant, caused a considerable deterioration in lung function and an increase in the profusion of small opacities. These findings are confirmed by the results of the second study, in which the men were much younger, and were exposed to dust for much shorter periods. Although, before these studies, little asbestos-related disease had been reported from Havelock, it would appear that past dust concentrations in the mill have been unacceptably high, probably at least 50 fibres $/ \mathrm{ml}(5$ $\times 10^{7}$ fibres $/ \mathrm{m}^{3}$ ). Since 1976 , however, measures have been taken to suppress the dust, and the levels of exposure have gradually been decreasing. A programme of regular health checks on all 2000 employees has recently started, which, together with continuous monitoring of the airborne dust, should appreciably reduce the risk of asbestos-related disease in the future.

\section{References}

' Rossiter CE, Bristol LJ, Cartier PH, et al. Radiographic changes in chrysotile asbestos mine and mill workers in Quebec. Arch Environ Health 1972;24:388-400.

${ }^{2}$ Ghezzi I, Aresini G, Vigliani EC. Il rischio di asbestosi in una miniera di amianto crisotilo. Med Lav 1972;63:189-211.

${ }^{3}$ International Labour Office. ILO 1980 International classification of radiographs of pneumoconioses. Geneva: ILO, 1980.

4 Cole TJ. Linear and proportional regression models in the prediction of ventilatory function. Journal of the Royal Statistical Society (series A) 1975;138:297-337.

${ }^{5}$ Viallat JR, Boutin C. Radiographic changes in chrysotile mine and mill ex-workers in Corsica. Lung 1980;157:155-63. 